\title{
Who is behind the scenes of the ICT backstage? A study of the ICT resources in local governments
}

\author{
Luis Felipe M. Ramos \\ Research Centre for Justice and Governance - \\ JusGov/University of Minho \\ id8856@alunos.uminho.pt \\ Delfina Soares \\ UNU-EGOV \\ soares@unu.edu
}

\author{
Mariana Lameiras \\ UNU-EGOV \\ lameiras@unu.edu \\ Luis Amaral \\ Centro ALGORITIMI, University of Minho \\ amaral@dsi.uminho.pt
}

\begin{abstract}
Given the current trend for digitalisation, Information and Communication Technologies (ICTs) have been playing a central role in institutional performance and development. This centrality impacts local e-government plans and strategies, with consequences for service delivery and interaction and engagement with citizens. This work provides a characterisation of the ICT resources in Portuguese municipalities and allows to understand the internal conditions under which municipalities strive to follow the digital government trend, focusing specifically on the internal organisation and procedures and the profile of human resources performing ICT-related tasks. Globally, data show how important the ICT function is for the Portuguese municipalities and reveals the aspects for which greater attention should be devoted. The need for training programs, team building, and resources' renewal is amongst the most prominent, on par with the importance of publicising and promoting the adoption of existing recommendations, instruments, tools, and services for a better knowledge, awareness and meaningful adoption and application.
\end{abstract}

\section{CCS CONCEPTS}

- Applied computing $\rightarrow$ Computers in other domains; Computing in government; E-government; Enterprise computing; IT governance; - Social and professional topics $\rightarrow$ Computing/technology policy; Government technology policy.

\section{KEYWORDS}

e-Government, Human Resources, Portugal, Municipalities, ICT characterisation

\section{ACM Reference Format:}

Luis Felipe M. Ramos, Mariana Lameiras, Delfina Soares, and Luis Amaral. 2021. Who is behind the scenes of the ICT backstage? A study of the ICT resources in local governments. In 14th International Conference on Theory and Practice of Electronic Governance (ICEGOV 2021), October 06-08, 2021,

Permission to make digital or hard copies of all or part of this work for personal or classroom use is granted without fee provided that copies are not made or distributed for profit or commercial advantage and that copies bear this notice and the full citation on the first page. Copyrights for components of this work owned by others than ACM must be honored. Abstracting with credit is permitted. To copy otherwise, or republish, to post on servers or to redistribute to lists, requires prior specific permission and/or a fee. Request permissions from permissions@acm.org.

ICEGOV 2021, October 06-08, 2021, Athens, Greece

(C) 2021 Association for Computing Machinery.

ACM ISBN 978-1-4503-9011-8/21/10 . \$ \$15.00

https://doi.org/10.1145/3494193.3494302
Athens, Greece. ACM, New York, NY, USA, 7 pages. https://doi.org/10.1145/ 3494193.3494302

\section{INTRODUCTION AND BACKGROUND}

The technological advances and innovations challenge every sector of society. The digital government theories stress the need and importance to use Information and Communication Technologies (ICTs) to promote and facilitate government-citizens interactions in order to move towards the digital transformation of governments. The Digital Government Evolution Model proposed by Janowski [1] shows how technology is central for all stages of the process, from digitisation and transformation to engagement (in the relationship with stakeholders) and contextualisation (emphasising the need to contextualise the impact in different sectors and communities). Indeed, the first and second stages of this model place technology in government and shed light on the impact of technology in internal government organisation and functioning. The impact and effects of digital government are immense and are multiplied on par with the different stakeholders involved and the objective pursued. There are many arguments sustaining its benefits. Either for better governance, to curb corruption, to foster transparency and trust in government activities [2,3], to promote citizen engagement [4] or to ease citizen-government interaction, digital government is consistently found as a 'magic solution' to some persistent and current problems, which have been highly accentuated by the Covid-19 pandemic.

Although the scientific and policy literature has been proliferating in this field since at least the last two decades, there are no such prolific contributions applied to local governments despite its importance as "hubs of human activity that are gaining in population and increased importance in the global economy" [5] (p. 151). The emphasis on the local government level is not yet thoroughly explored, namely regarding the impact of ICT usage in aspects as service delivery efficiency or participation levels. In the current particular context of Covid-19, the municipalities' key role as frontline responders is intensively emphasised by several international organisations [6, 7].

Aware of the convergent globalised world and the increasing challenges brought by technological innovations, municipalities struggle to take a stance in the digital realm, even with several shortcomings in the process, namely related to their administrative capacity [8] and limited (financial) resources [9]. And these shortcomings affect ICT usage from the point of view of the internal 
organisation and functioning and impact their online and digital presence greatly, hence affecting their relationship with citizens and other stakeholders.

Indeed, citizens' increasing expectations of public services have required constant administrative modernisation to streamline processes, reduce costs, provide information and services in a friendlier and more agile way throughout society, which shall provide a better quality of life for its citizens [10].

The results presented in this paper are drawn on data collected and analysed within the umbrella of a series of biennial studies about the internet presence of Portuguese municipalities. These studies aim to show how information technologies in general, and web technologies in particular, are used by local governments to inform citizens and make publicly available information regarding the municipality and its management, to facilitate navigation and interaction with the website, to make available online services as well as to foster e-participation and launch initiatives that can engage citizens in decision-making processes and municipal public policymaking [11]. Despite the web-centric approach that is being followed, the 'digital ecosystem' is considered with the characterization of the ICT function in terms of its human and financial resources, the infrastructure, the ICT function organisation and governance, digital applications and services, and regulations and guidelines. In specific, this paper presents the results focused on the resources allocated to the ICT function and provides a picture that excludes technical features related to the performance of this function at the local level.

This paper is organised as follows: the survey methodology is described in Section 2; findings are provided in Section 3; discussion of results and conclusions are presented in Section 4.

\section{METHODOLOGY}

Data was gathered through a survey addressed to all 308 municipalities in Portugal. Considering the aim of the study and the research questions formulated, a survey based on questionnaire was considered as the adequate method and data collection technique to use.

The structured questionnaire was developed based on an analysis of similar questionnaires and several brainstorming sessions with field experts. Its final version was validated by the project's partner, the Portuguese Agency for Administrative Modernization (AMA). It included 93 questions, most of them closed and mandatory, organised in nine dimensions: characterisation of the municipality, characterisation of the respondent, characterisation of the responsible for the ICT function, human resources allocated to the ICT function, financial resources allocated to the ICT function, ICT infrastructure, organisation and governance of the ICT function, digital applications and services, and regulations and guidelines.

Due to the considerable amount of data collected, it was decided to separate the findings in two different publications. This paper presents the results of 56 questions, focusing on human dimensions, and excludes the characterisation of technical dimensions. It covers the following aspects: characterisation of the municipality, characterisation of the respondent, characterisation of the responsible for the ICT function, human resources allocated to the ICT function, financial resources allocated to the ICT function, and organisational and governance of the ICT function.

The questionnaire was made available to municipalities through the LimeSurvey platform for five months. The data collected were exported and submitted to a 'cleaning' process, aiming to detect information that could indicate invalid answers, and for that reason, should be excluded from the analysis. Two such cases were identified, and after some phone contacts with the respective municipalities to clarify the doubts, they were excluded. Thus, from the 141 submitted questionnaires, 139 were considered valid and used for the analysis.

There are a few questions for which the total number of valid answers is lower than 139. It happens for one of two reasons: (i) some municipalities did not provide an answer to those specific questions, or (ii) the provided answer presented an incoherent and dissonant value with the question and the answers provided to some of the remaining questions; as such, it was considered that it resulted from an inaccurate interpretation from the respondent of what was being asked. In these cases, only the specific answer was removed and not the full municipality reply.

During the analysis, some data were aggregated to visualise the results better.

\section{FINDINGS}

The findings in this paper include a brief characterisation of the municipalities, the individual respondents of the questionnaire and who is responsible for the ICT function, in addition to results related to the human and financial resources allocated to the ICT function, as well as some data on the organisational and governance processes in the municipality. As previously indicated, the results of the technical dimensions surveyed shall be published separately.

\subsection{Characterisation of the municipality}

This dimension is related to information publicly available on trusted repositories and the answers were previously filled, so the respondents should only indicate if they agreed with the values indicated and, if not, correct the data.

Of the 308 municipalities targeted (all municipalities in the country), 139 (45\%) successfully submitted the questionnaire. Table 1 presents the data analysis of the municipality by populational dimension (large, medium, small) ${ }^{1}$. Among the respondent municipalities, more than half (53\%) are of small dimension, with 20.000 inhabitants or less. However, this number represents only $40 \%$ of the total number of small municipalities in the country, while $71 \%$ of the large municipalities replied to the questionnaire.

Most of the Portuguese municipalities (138 out of 308) are located in the interior of the country, while $41 \%$ are on the coastline and the remaining in the islands. Table 2 shows that, accordingly, most of the respondent municipalities were from the interior of the country (52\%), while those in the islands registered the lowest response rate (9 municipalities out of 30).

\footnotetext{
${ }^{1}$ For the purpose of this study, a small municipality is the one with a population of 20.000 or less inhabitants. In contrast, a medium municipality is the one with a population superior to 20.000 people and inferior or equal to 100.000 inhabitants, and a large municipality is the one with a population of more than 100.000 inhabitants.
} 
Table 1: Dimension of Municipalities $(n=139)$

\begin{tabular}{lcccc}
\hline Dimension Category & \# of Municipalities in the country & \multicolumn{3}{c}{ Answers } \\
\cline { 3 - 5 } & & \# of Answers & \% of Answers & $\%$ in the Category \\
\hline Large Municipality & 24 & 17 & $12 \%$ & $71 \%$ \\
Medium Municipality & 98 & 48 & $35 \%$ & $49 \%$ \\
Small Municipality & 186 & 74 & $53 \%$ & $40 \%$ \\
\hline
\end{tabular}

Table 2: Location of Municipalities $(\mathbf{n}=139)$

\begin{tabular}{|c|c|c|c|c|}
\hline \multirow[t]{2}{*}{ Zone Category } & \multirow{2}{*}{$\begin{array}{l}\text { \# of Municipalities in the } \\
\text { country }\end{array}$} & \multicolumn{3}{|c|}{ Answers } \\
\hline & & \# of Answers & $\%$ of Answers & $\%$ in the Category \\
\hline Interior & 138 & 72 & $52 \%$ & $52 \%$ \\
\hline Coastline & 140 & 58 & $42 \%$ & $41 \%$ \\
\hline Islands & 30 & 9 & $6 \%$ & $30 \%$ \\
\hline
\end{tabular}

Table 3: NUTS II Classification $(n=139)$

\begin{tabular}{|c|c|c|c|c|}
\hline \multirow[t]{2}{*}{ NUTS II Category } & \multirow{2}{*}{$\begin{array}{l}\text { \# of Municipalities in the } \\
\text { country }\end{array}$} & \multicolumn{3}{|c|}{ Answers } \\
\hline & & \# of Answers & $\%$ of Answers & $\%$ in the Category \\
\hline Alentejo & 58 & 26 & $19 \%$ & $45 \%$ \\
\hline Algarve & 16 & 5 & $4 \%$ & $31 \%$ \\
\hline Centre & 100 & 44 & $31 \%$ & $44 \%$ \\
\hline Lisbon & 18 & 8 & $6 \%$ & $44 \%$ \\
\hline North & 86 & 47 & $33 \%$ & $55 \%$ \\
\hline Autonomous Region of Madeira & 11 & 4 & $3 \%$ & $36 \%$ \\
\hline Autonomous Region of Azores & 19 & 5 & $4 \%$ & $26 \%$ \\
\hline
\end{tabular}

According to another territorial classification ${ }^{2}, 55 \%$ of the municipalities located in the North region of the country replied to the questionnaire, while in other regions (namely Alentejo, Centre and Lisbon), approximately $50 \%$ of the municipalities in each region submitted valid answers. Table 3 summarises the results.

\subsection{Characterisation of the respondent}

This section aims at characterising the municipalities' employee who replied to the questionnaire. From 139 respondents, 109 (78\%) stated that they are responsible for the ICT function. Considering that Section 3.3 provides the characterisation of those professionals, this section will focus on analysing the 30 remaining individual respondents to the questionnaire.

In two cases, the respondent claimed to be the mayor himself, and in another case, a city councilman. Five respondents alleged to be mid-level leaders from non-ICT areas, namely Management and Financial, Communication, Human Resources, and Administrative Modernisation. Another 14 were senior technicians, mostly from the IT area (computer specialists), although in one case, it was a senior technician from the communication area. The remaining eight respondents were IT assistants.

${ }^{2}$ NUTS - Nomenclature of Territorial Units for Statistics, established by Regulation (EC) $\mathrm{N}^{\circ} 1059 / 2003$ of the European Parliament and of the Council of 26 May 2003.

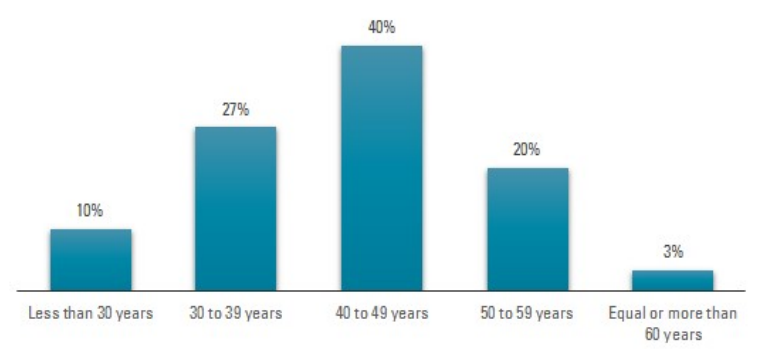

Figure 1: Respondents non-responsible for ICT function by age range $(n=30)$

Concerning their educational level, only eight stated to have secondary education, while the other 22 have post-secondary education in areas as diverse as IT, Management, Law, Economics, Sociology, Education, Chemistry, Communication, and International Relations. Figures 1 and 2 show the distribution by age range and gender of the 30 respondents who were not responsible for the ICT function in the municipalities.

Most of those respondents were municipal employees for many years. Twenty-five (83\%) of them had at least ten years of public service, while one of them had 32 years of public service. Just three had less than five years of experience in the municipality. In terms 


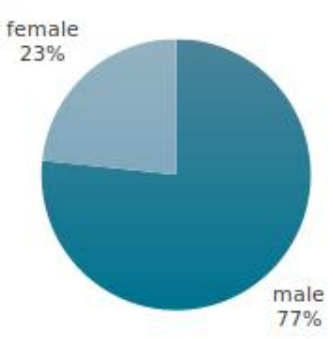

Figure 2: Respondents non-responsible for ICT function by gender $(\mathbf{n}=30)$

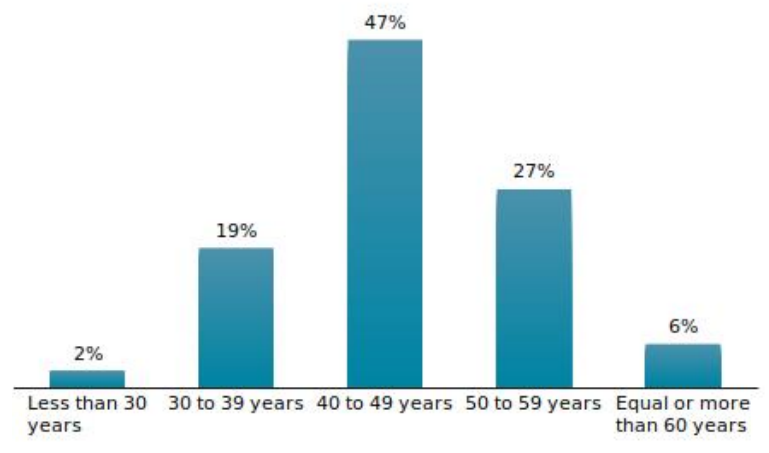

Figure 3: Respondents responsible for ICT function by age range $(n=139)$

of gender distribution, predominantly male respondents submitted the survey, contrasting with a minority of $23 \%$ female respondents.

\subsection{Characterisation of the Responsible for the ICT Function}

In order to identify the profile of the professionals responsible for the ICT function in the municipalities, the survey went through personal characteristics as age range, gender, and academic background. Some organisational features were also considered, as their role, whom they report to, their service time, and previous experience in similar roles, to evaluate the strategical value of this position for the municipalities.

Figures 3 and 4 show the distribution by age range and by gender of the respondents responsible for the ICT function in the municipalities surveyed.

The results show that the vast majority of the ICT employees are placed in the age range 40 to 59 years old, and that exists a culture of male predominancy. With $85 \%$ of the ICT employees dedicated to the ICT function being male, there is not gender balance, which is also consistent with the overall trend of male professionals in this area of expertise.

Regarding the respondents' educational level, 105 out of 139 declared to have post-secondary education, mostly in IT (74\%), while 32 have secondary education. Only two stated to have not completed secondary education. Also, in 22 cases, the respondents reported holding master's degrees.

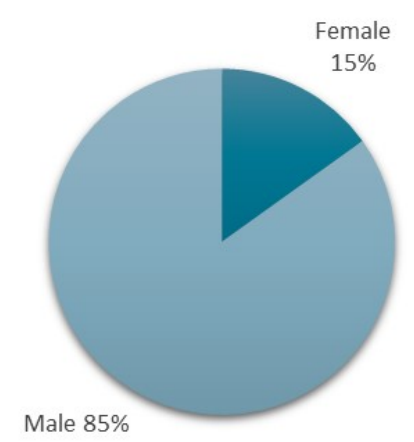

Figure 4: Respondents responsible for ICT function by gen$\operatorname{der}(\mathbf{n}=139)$

The average service time of these professionals in the municipalities is 16 years, with $69 \%$ of them occupying this position for more than ten years. Only in $4 \%$ of the municipalities surveyed the function if performed by someone who has been in the reported position for less than one year. To analyse the experience of these professionals, they were asked about the performance of similar duties in other organisations. Just $24 \%$ of them stated to have previous experience in the function, while $76 \%$ had never performed such duties before.

The importance of the function in the organisational structure can be measured by the responsibles' position in that structure. In eight municipalities, the function is performed by the mayor himself or another person who holds a position of election or political appointment, while in $40 \%$ of the cases, the responsible holds an intermediate position (department director or division head), and in the last $54 \%$ of cases other than managerial positions (computer specialist, computer technician, and assistant computer technician).

Also reflecting the importance of the ICT function for the municipality, $50 \%$ of the responsibles stated to report directly to the mayor or other authority of the Executive branch, while $40 \%$ report to senior management staff.

\subsection{Human Resources Allocated to the ICT Function}

The purpose of this section is to focus on the internal functioning conditions of the ICT field in municipalities considering its human resources. The aspects covered in this regard include the size of the team allocated to the ICT function, the age of its members, their educational level, as well as the rotation and renewal mechanisms.

On average, on the 138 respondent municipalities, the support teams are composed of seven members, with $88 \%$ of them reporting to have less than ten members on their teams. Only two municipalities stated to have more than 50 members on their teams, being one with 68 and the other with 128 members. It is important to highlight that ten municipalities indicated to have only one member in the ICT support team, and the other 34 stated to have only two members. 


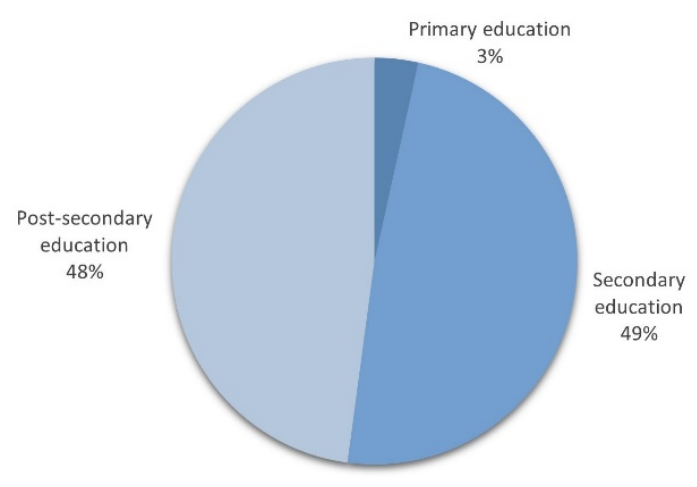

Figure 5: Educational level of the support team members (n =137)

Regarding the educational level of the support team members, only $48 \%$ of them have a post-secondary education, and $3 \%$ did not complete secondary education.

Most of the support team members (69\%) are between 40 and 60 years old. Members younger than 30 years old represent just 5\% of all support team members, and 80 municipalities reported not having any support team members younger than 30 years old.

Regarding staff renewal of human resources allocated to the ICT function, out of the 138 respondent municipalities, $42 \%$ did not have any new members in their support team in the previous five years, and $32 \%$ had only one new member on the period. On the other hand, $75 \%$ of the municipalities did not face a decrease in their support teams. These results suggest that scarce resources and the inability to actively and positively respond to the challenges and constant evolution of the ICT sector in terms of human resources can trigger additional difficulties.

\subsection{Financial Resources Allocated to the ICT Function}

The analysis of the financial resources allocated to the ICT function is framed by the amount of the budget set aside for the ICT function, presented as a percentage of the global budget of the 135 municipalities that provided this information, as well as an analysis of the segmentation of the overall ICT budget by specific headings.

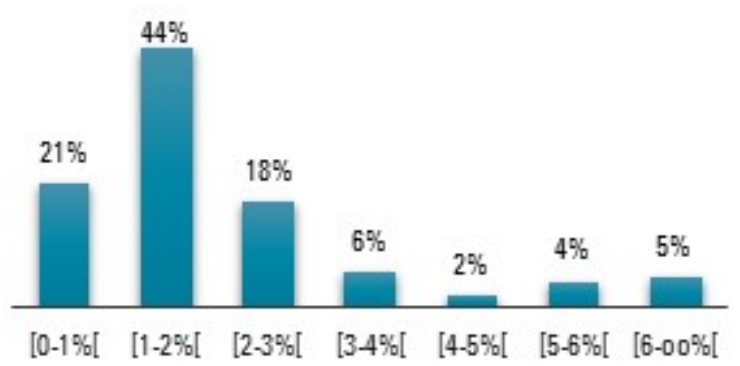

Figure 6: Percentage of global budget allocated to the ICT function $(\mathbf{n}=\mathbf{1 3 5})$

As Figure 6 shows, in $65 \%$ of the municipalities, the budget allocated to the ICT function is less than $2 \%$ of the municipality's global budget, and in $21 \%$ of the cases, it is less than $1 \%$. Only in $9 \%$ of the cases the budget exceeds $5 \%$ of the municipality's global budget. It is worth noting that in one municipality, located in the continental coastline of the region Centre and of small size, the budget allocated was reported as being $11.9 \%$ of the municipality's global budget.

Moreover, it was possible to notice the distribution of the ICT budget by headings, considering the 129 municipalities that provided that information. On average, the percentage of the budget allocated to "acquisition of goods (equipment and software)" is $24 \%$, followed by expenses with human resources (17\%). "Employee training" is the heading with the least weight in the allocated budget $(2 \%)$.

\subsection{Organisation and Governance of the ICT Function}

This section presents a characterisation of the organisational and governance structure of the ICT function.

Most municipalities (64\% out of 139) do not have a specific ICT area. In the 50 municipalities with a specific ICT area, $46 \%$ of them are under the responsibility of a city councilman, $34 \%$ under a deputy mayor, and $20 \%$ under the responsibility of the mayor himself. It is important to note that, as referred to in Section 3.3, a substantial percentage of those responsible for the ICT function do not have post-secondary education in the ICT field.

Concerning the decision to perform some of the main ICT functions in-house or to outsource them, it was presented a list with

Table 4: Age profile of support team members $(n=138)$

\begin{tabular}{|c|c|c|c|c|c|}
\hline & \multicolumn{5}{|c|}{ Age Range (Years) } \\
\hline & $<30$ & $30-40$ & $40-50$ & $50-60$ & $>60$ \\
\hline $\begin{array}{l}\text { Total of members of respondent } \\
\text { municipalities }(n=138) \text { by age range }\end{array}$ & $48(5 \%)$ & $234(22 \%)$ & $449(43 \%)$ & $276(26 \%)$ & $42(4 \%)$ \\
\hline $\begin{array}{l}\text { Municipalities without members in } \\
\text { the age range }(n=138)\end{array}$ & $111(80 \%)$ & $39(28 \%)$ & $25(18 \%)$ & $60(43 \%)$ & $119(86 \%)$ \\
\hline $\begin{array}{l}\text { Municipalities with prevailing age } \\
\text { range }(\mathrm{n}=103)^{\mathrm{a}}\end{array}$ & $5(5 \%)$ & $27(26 \%)$ & $52(51 \%)$ & $19(18 \%)$ & $0(0 \%)$ \\
\hline
\end{tabular}

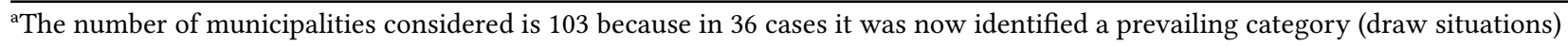


15 different functions ${ }^{3}$ and asked where they were performed. A total of $40 \%$ of the municipalities indicated to fully perform them in-house, while in $13 \%$ of the cases, more than $50 \%$ of the ICT function was outsourced. Systems development is the most outsourced activity, followed by auditing, compliance, and risk management. On the other hand, outsourcing management, IT operations, service management, and planning are the activities most municipalities (on average, 59\%) perform entirely in-house.

Regarding the adoption of ICT frameworks and methodologies, 113 municipalities (81\%) reported not applying any of the 13 presented $^{4}$, nor any other than those. The alleged reason, in $69 \%$ of the cases, was the lack of knowledge of their existence. However, among the municipalities adopting some framework and methodology, 22 use ITIL, five use Agile Scrum, and four use COBIT5. A similar result was observed regarding the adoption of standards. Most municipalities (60\%) reported not applying any of the six presented $^{5}$. In $41 \%$ of the cases, it was because they were unaware of the existence of those standards. ISO 9001:2000 is the most adopted standard used by 39 cities. The other five cities reported using ISO 9001:2015, and one using ISO 9001:2008.

The findings presented give an overview of the ICT function in Portuguese municipalities from the perspective of the internal conditions, resources and organization and governance processes. The next section is for the discussion of the findings and presentation of conclusions.

\section{DISCUSSION AND CONCLUSIONS}

Globally, the results from the survey show how vital the ICT function is for the Portuguese municipalities and reveals how much it can improve, with many aspects to enhance and promote.

That importance can be seen by the fact that in $50 \%$ of the municipalities, the person responsible for the ICT function reports directly to the mayor or other authority in the Executive branch. In some municipalities, the responsible for the ICT function is the mayor himself or another elected representative. However, this fact raises questions on the capability of the elected officials to perform adequately both roles they are responsible for and the risk of knowledge loss after the end of their mandates.

Concerning the profile of the responsible for the ICT function, on average, they have been public servants for 16 years, and $69 \%$ of them have been in the leadership position for more than ten years. Although they may have a good understanding of the municipality internal functioning, it does not mean they have the adequate background to be in that position, as only $24 \%$ had previous experience on the function, and 67 out of 139 do not have a technical background.

As data showed, there is substantial gender inequality in leadership positions for the ICT function, as $85 \%$ of the municipalities are controlled by men. This may result from the historical male

\footnotetext{
${ }^{3}$ Planning; Systems Development; Systems, Infrastructures and Communications Management; IT Operations; Risk Management; Information Security Management; Privacy and Data Protection Management; Business Continuity Management; Compliance; Service Management; External Hiring Management; Auditing; Change Management; Quality Management; and Innovation Management.

${ }^{4}$ COBIT5, Six Sigma, CBPP, Prince2, CMMI, CISM, TOGAF, Edison, SNABOK, Agile Scrum, HFI, ISTQB, and ITIL.

${ }^{5}$ ISO 20000, ISO 27000, ISO 27001, ISO 9001:2000; ISO 10303, ISSO 37120:2017.
}

predominance on technical functions or a consequence of fewer females applying for ICT positions in the public sector. Nevertheless, following international recommendations, the need to set up internal guidelines and procedures to promote a more gender-balanced leadership and work environment is undeniably important. The municipalities' autonomy in this regard may be somehow limited but should not hinder targeted actions to address gender inequality and imbalance at the government local level to the best of municipalities' capability and procedural agility.

The results also indicate that $80 \%$ of the responsibles for the ICT function are over 40 years old, being that $33 \%$ are over 50 years old. Older personnel may represent experienced and knowledgeable leadership with an adequate level of experience to manage the ICT function, and, considered alone, this indicator may not mean much. Nonetheless, it does not favour diversity inside municipalities' structures and shows that the public sector has not been opened to regenerate the system, and it is most susceptible to indulgence.

Analysing the human resources allocated to the ICT function, $52 \%$ of the personnel in the support team do not have any technical background, which can mean a lack of adequate knowledge to perform their activities better. Here, it was also possible to observe an age issue, as $73 \%$ of the personnel is above 40 years old, and $30 \%$ is older than 50 years. $80 \%$ of the municipalities do not have any employee in the support team with less than 30 years.

These results, combined with the fact that in $42 \%$ of the municipalities there was no addition of new employees to the ICT function in the previous five years, and in $32 \%$ of them there was the addition of only one member to the support team, representing a very low renewal rate, can be troublesome, considering the constant evolution of the ICT sector.

An adequate level of financial resources for training IT officers allows a higher level of knowledge and skills in technical activities, e.g., system development and maintenance [12]. Nonetheless, the budget allocation in the Portuguese municipalities is still low, with $65 \%$ of them applying, on average, less than $2 \%$ of the total budget for ICT-related activities, and only $2 \%$ of that amount being allocated for staff training.

The results presented in this paper show that of the available ICT budget, $1 / 4$ of the total is focused on acquiring goods (equipment and software). However, without adequate training, these goods may not be used to their full potential. It would be interesting to follow up the level of financial resources allocated to the ICT function and its distribution within the surveyed headings to see if there is an increase in the investment in this sector by the Portuguese municipalities, reflecting the importance of these functions to provide better digital services to the citizens.

A better-trained ICT personnel may impact the municipality's online presence and digital performance, as well as facilitate the adoption of ICT frameworks and methodologies, which represents a considerable gap identified in the survey. It may also contribute to the availability of new digital services' offer.

In the last years, Portugal has developed a regulatory framework to assist the adoption of user-friendly tools by the municipalities ${ }^{6}$,

\footnotetext{
${ }^{6}$ In which are inscribed the usabilidade.gov.pt initiative, the accessibility recommendations established by Decree-Law n ${ }^{\circ} 83 / 2018$, of 19 October, and the National Regulation for Digital Interoperability.
} 
but as identified in this work, most municipalities still are now aware of them. Further efforts must be made, not only to disclose these regulations but also to encourage their adoption.

As previously mentioned, the survey implemented included technical resources' dimensions that were excluded in this paper, meaning that a partial image of the ICT function in Portuguese municipalities is provided.

The municipalities can use this work as an opportunity for improvement and as an evidence-based tool for internal decisionmaking. It allows performance assessment and peer comparison. In conjunction with their general strategic priorities, this comparison can lead the way in performing the process of defining a digital transformation policy according to the national guidance and instructions postulated by the Digital Agenda for Portugal in the period $2020-2023^{7}$.

For national policymakers and governance structures, this work contributes to a clear perspective on the status quo of local ICT use and to think of national strategies and recommendations for digital government globally and targeted to the needs and interests of entities at all levels of government, so that conditions are created for the gradual and convergent development of digital governance in the country.

Also, this work is equally important both for academics and researchers in the field of digital governance, for showing how ICTs can be used to transform country governance mechanisms, as well as for ICT companies and service providers, particularly those with management as one of the main sectors of activity.

On another note, the data collection technique used could be complemented with other, namely interviews and/or focus groups. It would be interesting to understand the motivations and reasoning behind the current scenes of the IT backstage, which can be equated for future works. Comparing the Portuguese scenario with other countries would also bring the research to a higher level. In the national context, the same questionnaire is currently being considered for a biannual application, which will shed light on the evolution and maturity of the ICT function and conditions at the local government level.

\section{ACKNOWLEDGMENTS}

This work was supported by national funds through the Portuguese Foundation for Science and Technology (FCT), within the project UID/05749/2020, and the R\&D Units Project Scope: UIDB/00319/2020, and through the individual research grant 2020.04726.BD.

\section{REFERENCES}

[1] Tomasz Janowski. 2015. Digital government evolution: From transformation to contextualisation. Government Information Quarterly 32, 3, 221-236. https: //doi.org/10.1016/j.giq.2015.07.001

[2] Tiago Silva, António Tavares, and Mariana Lameiras. 2019. 'Trendy' Cities: Exploring the Adoption of Different Types of Social Media by Portuguese Municipalities. In: Panagiotopoulos P. et al. (eds) Electronic Participation. ePart 2019. Lecture Notes in Computer Science, vol 11686. Springer, Cham. https: //doi.org/10.1007/978-3-030-27397-2_3

[3] Anne Marie Warren, Ainin Sulaiman, and Noor Ismawati Jaafar. 2014. Social media effects on fostering online civic engagement and building citizen trust and trust in institutions. Government Information Quarterly 31, 2, 291-301. https: //doi.org/10.1016/j.giq.2013.11.007

[4] Enrique Bonsón, Sonia Royo, and Melinda Ratkai. 2015. Citizens' engagement on local governments' Facebook sites. An empirical analysis: The impact of different media and content types in Western Europe. Government Information Quarterly 32, 1, 52-62. https://doi.org/10.1016/j.giq.2014.11.001

[5] UN. United Nations E-Government Survey 2018: Gearing E-Government to Support Transformation Towards Sustainable and Resilient Societies. Retrieved April 16, 2021 from https://publicadministration.un.org/egovkb/Portals/egovkb/ Documents/un/2018-Survey/E-Government\%20Survey\%202018_FINAL\% 20for\%20web.pdf.

[6] UN. Policy Brief: COVID-19 in an Urban World. (July 2020). Retrieved April 16, 2021 from https://unsdg.un.org/sites/default/files/2020-07/sg_policy_brief_ covid_urban_world.pdf.

[7] Sameh Wahba, Maimunah Mohd Sharif, Mami Mizutori, and Lauren Sorkin. 2020. Cities are on the front lines of COVID-19. Blog Post (12 May 2020). Retrieved April 16, 2021 from https://blogs.worldbank.org/sustainablecities/cities-are-frontlines-covid-19.

[8] Mariana Lameiras, Tiago Silva, and António Tavares. 2018. An Empirical Analysis of Social Media Usage by Local Governments in Portugal. In Proceedings of the 11th International Conference on Theory and Practice of Electronic Governance (ICEGOV '18). Association for Computing Machinery, New York, NY, USA, 257268. https://doi.org/10.1145/3209415.3209503

[9] Nick Ellison \& Michael Hardey, 2014. (2014). Social Media and Local Government: Citizenship, Consumption and Democracy. Local Government Studies, 40(1), 21-40. https://doi.org/10.1080/03003930.2013.799066

[10] Ibrahim Kholilul Rohman and Linda Veiga. 2017. Against the Shadow: the Role of e-Government. In Proceedings of the 18th Annual International Conference on Digital Government Research (dg.o '17). Association for Computing Machinery, New York, NY, USA, 319-328. https://doi.org/10.1145/3085228.3085321

[11] Reference not provided to avoid authors' identification; to be included later

[12] Azmi Omar, Julian M Bass, and Peter Lowit. 2016. Exploring the Factors that Influence the Success of Insourced Government ICT Projects. The Electronic Journal of Information Systems in Developing Countries 77, 1, 1-21. https://doi. org/10.1002/j.1681-4835.2016.tb00564.x

\footnotetext{
${ }^{7}$ Issued by the Portuguese Government on 21 April 2020. Retrieved April 16, 2021 from https://www.dgae.gov.pt/comunicacao/destaques/plano-de-acao-para-atransicao-digital-.aspx.
} 